\title{
Matrix Metalloproteinase Neutrophil Gelatinase-Associated Lipocalin Complex Predicts Atrial Fibrillation Recurrence after Electrical Cardioversion in Obese Patients
}

\author{
Elzbieta Mlodawska ${ }^{a}$ Anna Tomaszuk-Kazberuk ${ }^{a}$ Paulina Lopatowska ${ }^{a}$ \\ Ewa Waszkiewicz $^{a}$ Hanna Bachorzewska-Gajewskab, d Jolanta Malyszko ${ }^{c}$ \\ Ewelina Michniewicz $^{a}$ Slawomir Dobrzycki ${ }^{b}$ Wlodzimierz Jerzy Musiala \\ Departments of a Cardiology, ${ }^{b}$ Invasive Cardiology, ${ }^{\mathrm{c}}$ Nephrology and ${ }^{\mathrm{d}}$ Clinical Medicine, \\ Medical University of Bialystok, Bialystok, Poland
}

\section{Key Words}

Atrial fibrillation $\cdot$ Cardioversion $\cdot$ MMP-NGAL $\cdot$ Obesity $\cdot$ Kidney function

\begin{abstract}
Background: There is not much data on matrix metalloproteinase neutrophil gelatinase-associated lipocalin (MMP-NGAL) complex in patients with atrial fibrillation (AF). Aim: The aim of the study was to assess the value of MMP-NGAL complex in predicting AF recurrence after electrical cardioversion. Methods: The serum levels of NGAL, cystatin C, interleukin-6, highsensitivity C-reactive protein, copeptin, MMP-NGAL complex, matrix metalloproteinase 2 , tissue inhibitor of metalloproteinase 1 , Von Willebrand factor, B-type natriuretic peptide and the urinary level of NGAL were evaluated before cardioversion. Results: A total of 83 patients with persistent AF were enrolled in the study. Left atrial diameter $(L A) \geq 4.5 \mathrm{~cm}$ was significantly associated with AF recurrence at follow-up $(p=0.009)$. In selected 39 obese patients, MMPNGAL complex was associated with AF recurrence $(p=0.03)$. If the concentration of MMPNGAL complex increased by $1 \mathrm{ng} / \mathrm{ml}$, the odds of AF recurrence increased by $4 \%$ (OR 1.04; CI: 1.00-1.08; $p=0.03$ ). MMP-NGAL complex did not correlate with AF recurrence in patients with a first episode of $A F$, in patients $\geq 65$ years of age and in patients with a $L A \geq 4.5 \mathrm{~cm}$ or with chronic kidney disease. Conclusions: It is known that the greater the BMI at baseline, the higher the likelihood of progression from paroxysmal to permanent AF. However, European Society of Cardiology (ESC) guidelines do not consider obese patients a population with a low likelihood of success of cardioversion. That is why we need a sensitive marker to predict sinus rhythm maintenance in such a population. We found that MMP-NGAL complex may predict $\mathrm{AF}$ recurrence after successful cardioversion in obese patients.


Mlodawska et al.: MMP-NGAL Complex Predicts Atrial Fibrillation Recurrence

\section{Introduction}

Atrial fibrillation (AF) is the most common arrhythmia, occurring in 1.5-2\% of the population $[1,2]$. It is known that AF increases morbidity and leads to disability or a limited quality of life [1]. Restoration of the sinus rhythm may relieve symptoms and improve left ventricular function. AF recurrence after cardioversion ranges from 60 up to $80 \%$ during the first year [3]. The most common factors related to AF recurrence are enlargement of the left atrium in echocardiography (ECG), long-lasting AF before cardioversion and age [3]. However, reliable clinical markers that predict the success of cardioversion have not been well determined.

Neutrophil gelatinase-associated lipocalin (NGAL) is a small extracellular protein with multiple functions. It plays a significant role in cardiovascular diseases. Elevated levels of NGAL have been found in patients with hypertension, ischemic heart disease, cerebrovascular disease and cancer [4]. Several studies have shown its prognostic value in patients with myocardial infarction and heart failure [5, 6]. One of the functions of NGAL is the formation of a complex with matrix metalloproteinase 9 (MMP-9) [7]. By forming the MMP-NGAL complex, NGAL protects MMP-9 from proteolytic degradation increasing the enzymatic activity of MMP-9, which may cause fibrosis and cardiac remodeling [4, 8]. Several studies have indicated that remodeling of atria contributes to the recurrence or perpetuation of $\mathrm{AF}$ [3]. To date, there is not much data on MMP-NGAL complex in patients with AF.

The aim of the study was to assess the value of MMP-NGAL complex in predicting AF recurrence after electrical cardioversion.

\section{Patients and Methods}

Study Population

We included 83 consecutive patients with persistent AF referred to the cardiology department for electrical cardioversion in the years 2013-2014. The study protocol conformed to the ethical guidelines of the 1975 Declaration of Helsinki and was approved by the local ethics committee. Informed consent was received from the participants. At study entry, the medical history of the patients was recorded, and all patients underwent physical examination, resting ECG and routine transthoracic ECG.

Blood Samples and Biomarker Assays

Venous blood samples were collected before cardioversion, centrifuged within $30 \mathrm{~min}$ and stored at $-80^{\circ}$ C. Serum creatinine, B-type natriuretic peptide, urinary NGAL and Von Willebrand factor levels were assessed using standard laboratory methods in a local laboratory. The serum levels of NGAL, cystatin C, interleukin 6, high-sensitivity C-reactive protein, copeptin, matrix metalloproteinase 2, tissue inhibitor of metalloproteinase 1 and MMP-NGAL complex were evaluated using commercially available ELISA assays according to the manufacturer's protocol. The NGAL level was measured using the ELISA kit (BioPorto Diagnostics, Hellerup, Denmark ). Furthermore, the cystatin C level (BioVendor Research and Diagnostic Products, Brno, Czech Republic), high-sensitivity C-reactive protein level (LDN, Nordhorn, Germany), copeptin level (Phoenix Pharmaceuticals, Inc., Karlsruhe, Germany), as well as the interleukin-6, MMP-NGAL complex, matrix metalloproteinase 2 and tissue inhibitor of metalloproteinase 1 levels (R\&D Systems, Minneapolis, Minn., USA) were measured.

\section{Cardioversion Protocol}

Electrical cardioversion was performed under short general i.v. anesthesia according to the standard protocol. Unsuccessful cardioversion was defined as no sinus rhythm recurrence.

\section{Echocardiographic Analysis}

Left atrial diameter (LA) and left ventricular ejection fraction were assessed by transthoracic ECG using the modified biplane Simpson's method (Ultrasound System Sonos 5500; Philips, Andover, Mass., USA), equipped for harmonic imaging with a 3.6-MHz transducer and derived in accordance with the recommendations of the European Society of Echocardiography [9]. 
Medicine

Follow-up

The AF recurrence was assessed after $57 \pm 34$ days of follow-up.

Statistical Analysis

Data are expressed as means and standard deviations. Relative frequencies are used to present categorical variables. Student's t test, the Mann-Whitney U test and $\chi^{2}$ test were used for statistical analysis where applicable. Logistic regression was used to test the association between variables and outcome. A $p$ value $<0.05$ was considered statistically significant. The statistic software STATISTICA (data analysis software system) version 12 was used.

\section{Results}

Baseline Characteristics of the Population

A total of 83 patients with persistent AF (female, 42\%; mean age $64 \pm 10$ years) were enrolled in the study. The mean BMI was $30.75 \pm 5.20$. Hypertension was present in $76 \%$ $(n=63)$, diabetes in 18\% ( $n=15)$, chronic kidney disease (CKD) in 43\% ( $n=35)$, ischemic heart disease in $18 \%(n=15)$ and chronic heart failure in $34 \%(n=28)$ of the patients. The mean left ventricular ejection fraction assessed by ECG was $51 \pm 10 \%$, and the mean LA was $4.6 \pm 0.5 \mathrm{~cm}$. The first episode of AF was present in $43 \%(n=35)$ of the patients. The mean time of the current AF episode duration was 71 days (range: 1-720), the mean time of AF history was 28 months (range: $0.5-240$ ). The mean $\mathrm{CHA}_{2} \mathrm{DS}_{2} \mathrm{VASC}$ score was 2.48 (range: $0-8$ ), while the mean HAS-BLED score was 0.64 (range: $0-3$ ).

AF recurrence was evaluated after $57 \pm 34$ days of follow-up. Cardioversion was unsuccessful in $6 \%(n=5)$. During follow-up, 33\% $(n=19)$ of the patients experienced AF recurrence. The clinical characteristics of the population are shown in table 1.

\section{Factors Associated with AF Recurrence}

LA $\geq 4.5 \mathrm{~cm}$ was significantly associated with AF recurrence on follow-up ( $\mathrm{p}=0.009)$, although there were no significant clinical factors associated with AF recurrence (table 1).

In the second part of the analysis, we selected different subgroups of patients, such as patients with a first episode of AF, patients $\geq 65$ years of age, obese patients (with a BMI $\geq 30$ ), patients with LA $\geq 4.5 \mathrm{~cm}$ or with CKD [estimated glomerular filtration rate (eGFR) $<60 \mathrm{ml}$ / $\left.\min / 1.73 \mathrm{~m}^{2}\right]$.

In the multivariate regression analysis (under 95\% CI), there was an insignificant effect of MMP-NGAL complex $(\mathrm{p}=0.7)$ and obesity $(\mathrm{p}=0.09)$ on AF recurrence. The significance for the interaction of these two terms has been achieved (coefficient $=0.04, \mathrm{OR}=1.04, \mathrm{p}=0.048$ ). This may suggest a predictive value of MMP-NGAL complex for electrical cardioversion in obese population.

\section{Obese Patients}

A total of 39 obese patients (female, 43\%; mean age $62 \pm 10$ years) were selected from the study population. AF recurrence was evaluated during $60 \pm 38$ days of follow-up. Cardioversion was unsuccessful in 5\% $(n=2)$. During follow-up, $26 \%(n=10)$ of the patients experienced $\mathrm{AF}$ recurrence. Baseline characteristics of the obese population are shown in table 2.

\section{Factors Associated with AF Recurrence on Follow-Up in Obese Patients}

AF recurrence in obese patients was associated with anemia $(\mathrm{p}=0.01)$, history of stroke $(p=0.01), L A \geq 4.5 \mathrm{~cm}(p=0.009)$ and HAS-BLED score $(p=0.03)$. A laboratory predictor of AF recurrence was MMP-NGAL complex ( $\mathrm{p}=0.03$ ) (table 2). 
Table 1. Baseline characteristics of the population divided into two groups according to AF recurrence

\begin{tabular}{|c|c|c|c|c|}
\hline & $\begin{array}{l}\text { All patients } \\
(\mathrm{n}=83)\end{array}$ & $\begin{array}{l}\text { AF recurrence } \\
(\mathrm{n}=19)\end{array}$ & $\begin{array}{l}\text { SR maintenance } \\
(\mathrm{n}=38)\end{array}$ & $\mathrm{p}$ value \\
\hline Females & 42 & 53 & 40 & 0.3 \\
\hline Age, years & $64(10)$ & $63.4(12.3)$ & $63.6(10.7)$ & 0.9 \\
\hline Age $\geq 65$ years & 51 & 47 & 42 & 0.7 \\
\hline BMI & $30.75(5.20)$ & $30.6(6)$ & $130.3(4.8)$ & 0.8 \\
\hline eGFR, $\mathrm{ml} / \mathrm{min} / 1.73 \mathrm{~m}^{2}$ & $61(15)$ & $60.9(13)$ & $61.6(17.4)$ & 0.9 \\
\hline $\mathrm{LA}, \mathrm{mm}$ & $4.57(0.51)$ & $4.7(0.3)$ & $4.5(0.5)$ & 0.07 \\
\hline $\mathrm{LA}>4.5, \%$ & 23 & 90 & 55 & 0.009 \\
\hline Ejection fraction, \% & $50(10)$ & $50(8)$ & $50(10)$ & 0.7 \\
\hline CHA2-DS2-VASc score ${ }^{\mathrm{a}}$ & $2.48(1.63)$ & $2.79(2.1)$ & $2.3(1.45)$ & 0.3 \\
\hline HAS-BLED score ${ }^{\mathrm{b}}$ & $0.64(0.73)$ & $0.79(0.71)$ & $0.5(0.65)$ & 0.2 \\
\hline \multicolumn{5}{|l|}{ Arrhythmia history } \\
\hline First episode of AF & 43 & 37 & 50 & 0.3 \\
\hline Time of AF history, months & $28(41)$ & $23(32)$ & $21(30)$ & 0.6 \\
\hline Duration of AF episode, days & $71(100)$ & $48(58)$ & $72(58)$ & 0.1 \\
\hline \multicolumn{5}{|l|}{ History } \\
\hline Hypertension & 76 & 79 & 74 & 0.6 \\
\hline Diabetes mellitus & 18 & 10 & 24 & 0.2 \\
\hline Coronary artery disease & 18 & 15 & 15 & 1 \\
\hline Chronic heart failure & 34 & 42 & 39 & 0.8 \\
\hline CKD & 43 & 39 & 45 & 0.6 \\
\hline Anemia & 10 & 21 & 8 & 0.1 \\
\hline Previous myocardial infarction & 5 & 0 & 5 & 0.3 \\
\hline Previous PCI & 6 & 0 & 5 & 0.3 \\
\hline \multicolumn{5}{|l|}{ End-point } \\
\hline AF recurrence on follow-up & 33 & - & - & - \\
\hline \multicolumn{5}{|l|}{ Biomarkers } \\
\hline $\mathrm{hs}-\mathrm{CRP}, \mathrm{ng} / \mathrm{ml}$ & $91,162(80,852)$ & $8,594(87,404)$ & $100,640(79,781)$ & 0.3 \\
\hline IL-6, pg/ml & $4.94(5)$ & $6.05(8.03)$ & $5.3(5.70)$ & 0.3 \\
\hline MMP-2, ng/ml & $227.69(54)$ & $248.56(60)$ & $227.2(54)$ & 0.3 \\
\hline TIMP-1, ng/ml & $178.22(57)$ & $191(54)$ & $172(61)$ & 0.3 \\
\hline MMP-NGAL complex, ng/ml & $58.71(42)$ & $63.1(30)$ & $55.4(44)$ & 0.2 \\
\hline sNGAL, ng/ml & $114.73(50)$ & $105.14(35)$ & $124.4(55)$ & 0.4 \\
\hline uNGAL, ng/ml & $26.49(33)$ & $28.79(34)$ & $26.3(38)$ & 0.7 \\
\hline Cystatin C, ng/ml & $861.41(352)$ & $832.8(304)$ & $914.2(444)$ & 0.4 \\
\hline $\mathrm{BNP}, \mathrm{pg} / \mathrm{ml}$ & $248.87(217)$ & $304.4(182)$ & $262.7(275)$ & 0.09 \\
\hline vWF, $\%$ & $163.41(64)$ & $155.13(57)$ & $157.9(53)$ & 0.8 \\
\hline Copeptin, ng/ml & $1.12(0.37)$ & $1.08(0.26)$ & $1.1(0.41)$ & 0.7 \\
\hline
\end{tabular}

Values are expressed as mean (standard deviation) or percentages. PCI = Percutaneous coronary interventions; SR = sinus rhythm; BNP = B-type natriuretic peptide; uNGAL = urinary NGAL; $\mathrm{SNGAL}=$ serum NGAL; vWF = von Willebrand factor; IL-6 = interleukin 6; hs CRP = high-sensitivity C-reactive protein.

${ }^{\text {a } C H A 2-D S 2-V A S c}$ score: $\mathrm{C}=$ Congestive heart failure/left ventricular dysfunction; $\mathrm{H}=$ hypertension; $\mathrm{A}=$ age $\geq 75$ (doubled); $\mathrm{D}=$ diabetes; $\mathrm{S}=$ stroke (doubled); $\mathrm{V}=$ vascular disease; $\mathrm{A}=$ age $65-74$ years; $\mathrm{S}=$ sex category (female). ${ }^{\mathrm{b}}$ HAS-BLED score: $\mathrm{H}=$ Hypertension; $\mathrm{A}=$ abnormal liver or renal function; $\mathrm{S}=$ stroke; $\mathrm{B}=$ bleeding; $\mathrm{L}=$ labile INR; E = elderly; $\mathrm{D}$ = drugs or alcohol. 
Table 2. Baseline characteristics of the obese population divided into two groups according to AF recurrence

\begin{tabular}{|c|c|c|c|c|}
\hline & $\begin{array}{l}\text { All patients } \\
(\mathrm{n}=39)\end{array}$ & $\begin{array}{l}\text { AF recurrence } \\
(n=10)\end{array}$ & $\begin{array}{l}\text { SR maintenance } \\
(\mathrm{n}=17)\end{array}$ & $\begin{array}{l}\mathrm{p} \\
\text { value }\end{array}$ \\
\hline Females & 43 & 60 & 36 & 0.2 \\
\hline Age, years & $62(10)$ & $64(11)$ & $59(10)$ & 0.2 \\
\hline Age $\geq 65$ years & 40 & 50 & 30 & 0.2 \\
\hline BMI & $34.7(4.25)$ & $34.1(6)$ & $34.5(3)$ & 0.8 \\
\hline $\mathrm{eGFR}, \mathrm{ml} / \mathrm{min} / 1.73 \mathrm{~m}^{2}$ & $60(16)$ & $58(14)$ & $61(19)$ & 0.6 \\
\hline $\mathrm{LA}, \mathrm{mm}$ & $4.7(0.46)$ & $4.7(0.2)$ & $4.6(0.5)$ & 0.4 \\
\hline $\mathrm{LA}, \geq 4.5, \%$ & 70 & 100 & 52 & 0.009 \\
\hline Ejection fraction, \% & $50(10)$ & $50(8)$ & $50(10)$ & 0.7 \\
\hline CHA2-DS2-VASc score ${ }^{a}$ & $2.7(1.89)$ & $3.5(2.5)$ & $2.3(1.5)$ & 0.2 \\
\hline HAS-BLED score ${ }^{\mathrm{b}}$ & $0.6(0.78)$ & $1(0.66)$ & $0.35(0.6)$ & 0.03 \\
\hline \multicolumn{5}{|l|}{ Arrhythmia history } \\
\hline First episode of AF & 40 & 30 & 47 & 0.3 \\
\hline Time of AF history, months & $27(31)$ & $32(37)$ & $21(27)$ & 0.3 \\
\hline Duration of AF episode, days & $66(69)$ & $63(106)$ & $81(60)$ & 0.1 \\
\hline \multicolumn{5}{|l|}{ History } \\
\hline Hypertension & 90 & 90 & 82 & 0.5 \\
\hline Diabetes mellitus & 30 & 30 & 47 & 0.3 \\
\hline Coronary artery disease & 30 & 20 & 23 & 0.8 \\
\hline Chronic heart failure & 40 & 40 & 41 & 0.9 \\
\hline CKD & 40 & 40 & 41 & 0.9 \\
\hline Anemia & 10 & 30 & 0 & 0.01 \\
\hline Previous myocardial infarction & 10 & 0 & 6 & 0.4 \\
\hline Previous PCI & 10 & 0 & 6 & 0.4 \\
\hline \multicolumn{5}{|l|}{ End-point } \\
\hline AF recurrence on follow-up & 26 & - & - & - \\
\hline \multicolumn{5}{|l|}{ Biomarkers } \\
\hline hs-CRP, ng/ml & $114,123(91,488)$ & $129,159(109,396)$ & $105,684(93,689)$ & 0.5 \\
\hline IL-6, pg/ml & $5.1(5.5)$ & $6.05(8.03)$ & $5.3(5.70)$ & 0.7 \\
\hline MMP-2, ng/ml & $231.6(55)$ & $256.8(60)$ & $230.3(54)$ & 0.2 \\
\hline TIMP-1, ng/ml & $183.9(60)$ & $210.6(20)$ & $178.3(52)$ & 0.2 \\
\hline MMP-NGAL complex, ng/ml & $56.1(35)$ & $66.3(20)$ & $43.7(24)$ & 0.03 \\
\hline $\mathrm{sNGAL}, \mathrm{ng} / \mathrm{ml}$ & $110(42)$ & $102.9(40)$ & $116.7(42)$ & 0.4 \\
\hline uNGAL, ng/ml & $34.2(43)$ & $29.3(42)$ & $40.9(53)$ & 0.9 \\
\hline Cystatin C, ng/ml & $867.6(459)$ & $910.9(379)$ & $905.7(608)$ & 0.5 \\
\hline $\mathrm{BNP}, \mathrm{pg} / \mathrm{ml}$ & $233.7(185)$ & 283.7 (149) & $224.6(238)$ & 0.1 \\
\hline $\mathrm{vWF}, \%$ & $172.6(64)$ & $189(62)$ & $168(54)$ & 0.4 \\
\hline Copeptin, ng/ml & $1.2(0.31)$ & $1.08(0.24)$ & $1.1(0.35)$ & 0.5 \\
\hline
\end{tabular}

Values are expressed as mean (standard deviation) or percentages. PCI = Percutaneous coronary interventions; $\mathrm{SR}=$ sinus rhythm; BNP = B-type natriuretic peptide; $\mathrm{UNGAL}=$ urinary NGAL; $\mathrm{sNGAL}=$ serum NGAL; vWF = von Willebrand factor; IL-6 = interleukin 6; hs-CRP = high-sensitivity C- reactive protein.

${ }^{\text {a }}$ CHA2-DS2-VASc score: $\mathrm{C}=$ Congestive heart failure/left ventricular dysfunction; $\mathrm{H}=$ hypertension; $\mathrm{A}=$ age $\geq 75$ (doubled); $\mathrm{D}=$ diabetes; $\mathrm{S}=$ stroke (doubled); $\mathrm{V}=$ vascular disease; $\mathrm{A}=$ age 65-74 years; $\mathrm{S}=$ sex category (female). ${ }^{b}$ HAS-BLED score: $\mathrm{H}=$ Hypertension; $\mathrm{A}=$ abnormal liver or renal function; $\mathrm{S}=$ stroke; $\mathrm{B}=$ bleeding; L = labile INR; E = elderly; D = drugs or alcohol. 


\section{CardioRenal Medicine}

Table 3. Logistic regression model for the odds of AF recurrence

\begin{tabular}{l|l}
\hline Cardiorenal Med 2017;7:11-20 \\
\hline DOI: 10.1159/000448225 & $\begin{array}{l}\text { ( 2)16 S. Karger AG, Basel } \\
\text { www.karger.com/crm }\end{array}$ \\
\hline
\end{tabular}

Mlodawska et al.: MMP-NGAL Complex Predicts Atrial Fibrillation Recurrence

\begin{tabular}{llll}
\hline & $\begin{array}{c}\text { Odds } \\
\text { ratio }\end{array}$ & & p5\% CI \\
\hline hs-CRP, ng/ml & 1.00 & $0.99-1.00$ & 0.54 \\
IL-6, pg/ml & 1.05 & $0.92-1.19$ & 0.4 \\
MMP-2, ng/ml & 1.00 & $0.99-1.02$ & 0.2 \\
TIMP-1, ng/ml & 1.01 & $0.99-1.02$ & 0.1 \\
MMP-NGAL complex, ng/ml & 1.04 & $1.03-1.08$ & 0.03 \\
sNGAL, ng/ml & 0.99 & $0.97-1.01$ & 0.4 \\
uNGAL, ng/ml & 0.93 & $0.98-1.01$ & 0.9 \\
Cystatin C, ng/ml & 1.00 & $0.99-1.20$ & 0.9 \\
BNP, pg/ml & 1.00 & $0.99-1.00$ & 0.5 \\
vWF, \% & 1.00 & $0.99-1.02$ & 0.4 \\
Copeptin, ng/ml & 0.33 & $0.01-5.99$ & 0.4 \\
\hline
\end{tabular}

$\mathrm{BNP}=\mathrm{B}$-type natriuretic peptide; $\mathrm{uNGAL}=$ urinary NGAL; $\mathrm{SNGAL}=$ serum NGAL; vWF = von Willebrand factor; IL-6 = interleukin 6; hs$\mathrm{CRP}=$ high-sensitivity $\mathrm{C}$-reactive protein.
Table 4. MMP-NGAL complex as a biomarker of $\mathrm{AF}$ recurrence in the different subgroups of patients

\begin{tabular}{lccl}
\hline Patients & $\begin{array}{l}\text { MMP-NGAL complex } \\
\text { in patients with AF } \\
\text { recurrence, ng/ml }\end{array}$ & $\begin{array}{l}\text { MMP-NGAL complex } \\
\text { in patients with sinus } \\
\text { rhythm, ng/ml }\end{array}$ & p value \\
\hline Obese & $66.3(20)$ & $43.7(24)$ & 0.03 \\
$\geq 65$ years old & $57.5(25)$ & $56.7(31)$ & 0.9 \\
With first episode AF & $51.63(23)$ & $67.69(50)$ & 0.4 \\
With LA $\geq 4.5 \mathrm{~cm}$ & $62(29)$ & $50(33)$ & 0.2 \\
With CKD & $58.8(24)$ & $46.5(22)$ & 0.2 \\
\hline
\end{tabular}

Values are expressed as mean (standard deviation).

\section{The Logistic Regression Model}

If the concentration of MMP-NGAL complex increased by $1 \mathrm{ng} / \mathrm{ml}$, the odds of AF recurrence increased by 4\% (OR 1.04; CI: 1.00-1.08; $\mathrm{p}=0.03$ ) (table 3).

\section{Other Analyzed Subgroups}

In selected subgroups of patients, such as patients with a first episode of AF, patients $\geq 65$ years of age, patients with LA $\geq 4.5 \mathrm{~cm}$ or with CKD (eGFR $<60 \mathrm{ml} / \mathrm{min} / 1.73 \mathrm{~m}^{2}$ ), MMP-NGAL complex did not correlate with AF recurrence (table 4). The rest of the parameters performed and analyzed are shown in table 5.

\section{Discussion}

No previous study has assessed the prognostic value of MMP-NGAL complex in patients with AF undergoing electrical cardioversion. In our study, we found that MMP-NGAL complex may predict AF recurrence after successful cardioversion in obese patients.

CKD is present in $10-15 \%$ of the AF patients $[10,11]$. Renal failure may increase the risk of AF-related cardiovascular complications. On the other hand, the risk of new-onset AF is raised in patients with CKD [12]. In the Ibaraki Prefectural Health Study, it was shown that CKD in combination with anemia is synergistically associated with a higher risk for AF onset 
Table 5. Biomarkers of AF recurrence in subgroups of patients

\begin{tabular}{|c|c|c|c|}
\hline & AF recurrence & SR maintenance & $\mathrm{p}$ value \\
\hline \multicolumn{4}{|l|}{ Patients with $L A \geq 4.5 \mathrm{~cm}$} \\
\hline hs-CRP, ng/ml & $92,295.26(90,461)$ & $91,147(79,165)$ & 0.9 \\
\hline IL-6, pg/ml & $6.37(8.42)$ & $4.21(3.19)$ & 0.3 \\
\hline MMP-2, ng/ml & $251.76(62)$ & $235.2(48)$ & 0.3 \\
\hline TIMP-1, ng/ml & $192.21(55)$ & $177.23(37)$ & 0.3 \\
\hline MMP-NGAL complex, ng/ml & $62(29)$ & $50(33)$ & 0.2 \\
\hline $\mathrm{sNGAL}, \mathrm{ng} / \mathrm{ml}$ & $105.2(37)$ & $116.3(45)$ & 0.4 \\
\hline uNGAL, ng/ml & $30.3(35)$ & $32.5(46)$ & 0.8 \\
\hline Cystatin C, ng/ml & $833(312)$ & $951.8(544)$ & 0.4 \\
\hline $\mathrm{BNP}, \mathrm{pg} / \mathrm{ml}$ & $284(161)$ & $282(300)$ & 0.9 \\
\hline $\mathrm{vWF}, \%$ & $147(57)$ & $169(60)$ & 0.3 \\
\hline Copeptin, ng/ml & $1.06(0.27)$ & $1.07(0.32)$ & 0.9 \\
\hline \multicolumn{4}{|l|}{ Patients with a first episode $A F$} \\
\hline hs-CRP, ng/ml & $52,143(68,609)$ & $74,593(61,769)$ & 0.4 \\
\hline IL-6, pg/ml & $5.81(10.66)$ & $3.87(2.98)$ & 0.4 \\
\hline MMP-2, ng/ml & $281.52(71)$ & $237.4(46)$ & 0.07 \\
\hline TIMP-1, ng/ml & $170.3(36)$ & $171(24)$ & 0.9 \\
\hline MMP-NGAL complex, ng/ml & $51.63(23)$ & $67.69(50)$ & 0.4 \\
\hline $\mathrm{sNGAL}, \mathrm{ng} / \mathrm{ml}$ & $107.3(34)$ & $128.43(64)$ & 0.4 \\
\hline uNGAL, ng/ml & $20.84(14)$ & $33(48)$ & 0.5 \\
\hline Cystatin C, ng/ml & 792.62 (139) & $849.69(266)$ & 0.6 \\
\hline $\mathrm{BNP}, \mathrm{pg} / \mathrm{ml}$ & 215 (127) & $322(348)$ & 0.4 \\
\hline vWF, \% & $134(34)$ & $148(40)$ & 0.4 \\
\hline Copeptin, ng/ml & $0.96(0.30)$ & $1.10(0.41)$ & 0.4 \\
\hline \multicolumn{4}{|l|}{ Patients $\geq 65$ years of age } \\
\hline hs-CRP, ng/ml & $98,573(99,771)$ & $73,526(58,242)$ & 0.4 \\
\hline IL-6, pg/ml & $8.44(9)$ & $5.32(5)$ & 0.3 \\
\hline MMP-2, ng/ml & $234.2(32)$ & $237.9(64)$ & 0.8 \\
\hline TIMP-1, ng/ml & $193.1(55.9)$ & $157.9(55)$ & 0.1 \\
\hline MMP-NGAL complex, ng/ml & $57.5(25)$ & $56.7(31)$ & 0.9 \\
\hline $\mathrm{sNGAL}, \mathrm{ng} / \mathrm{ml}$ & $108(29)$ & $104(58)$ & 0.1 \\
\hline uNGAL, ng/ml & $38(47)$ & $37(58)$ & 0.9 \\
\hline Cystatin C, ng/ml & $987(363)$ & $1,062(610)$ & 0.7 \\
\hline $\mathrm{BNP}, \mathrm{pg} / \mathrm{ml}$ & $372(189)$ & 344 (258) & 0.7 \\
\hline $\mathrm{vWF}, \%$ & $201(45)$ & $152(46)$ & 0.05 \\
\hline Copeptin, ng/ml & $1.13(0.24)$ & $1.13(0.43)$ & 0.9 \\
\hline \multicolumn{4}{|l|}{ Patients with $C K D$} \\
\hline hs-CRP, ng/ml & $57,895(90,561)$ & $96,708(82,452)$ & 0.3 \\
\hline IL-6, pg/ml & $7.66(10)$ & $4.39(2)$ & 0.2 \\
\hline MMP-2, ng/ml & $254.5(55)$ & $231.7(56)$ & 0.3 \\
\hline TIMP-1, ng/ml & $173(38)$ & $193(80)$ & 0.5 \\
\hline MMP-NGAL complex, ng/ml & $58.8(24)$ & $46.5(22)$ & 0.2 \\
\hline $\mathrm{sNGAL}, \mathrm{ng} / \mathrm{ml}$ & $131.4(17)$ & $133(55)$ & 0.9 \\
\hline uNGAL, $\mathrm{ng} / \mathrm{ml}$ & $33(26)$ & $18(22)$ & 0.2 \\
\hline Cystatin C, ng/ml & $897.6(447)$ & 1,107 (577) & 0.4 \\
\hline $\mathrm{BNP}, \mathrm{pg} / \mathrm{ml}$ & 291 (191) & $262(223)$ & 0.7 \\
\hline vWF, \% & $162(56)$ & $173(59)$ & 0.7 \\
\hline Copeptin, ng/ml & $0.99(0.28)$ & $1.09(0.43)$ & 0.6 \\
\hline
\end{tabular}

Values are expressed as mean (standard deviation). SR = Sinus rhythm; BNP = B-type natriuretic peptide; uNGAL = urinary NGAL; sNGAL = serum NGAL; vWF = von Willebrand factor; IL-6 = interleukin 6; hs-CRP = highsensitivity C-reactive protein. 
[13]. It is estimated that $19-24 \%$ of the patients with CKD are diagnosed with $\mathrm{AF}[14,15]$. It was also reported that concomitant CKD increases the recurrence of AF after catheter ablation [16]. In the majority of studies, CKD was defined as an eGFR $<60 \mathrm{ml} / \mathrm{min} / 1.73 \mathrm{~m}^{2}$.

In the present study, a decreased eGFR did not correlate with AF recurrence as the mean eGFR was $61 \pm 15 \mathrm{ml} / \mathrm{min} / 1.73 \mathrm{~m}^{2}$. However, when we used a more sensitive tool such as MMP-NGAL complex, it showed the relation between renal function and AF recurrence. We demonstrated that if the concentration of MMP-NGAL complex increased by $1 \mathrm{ng} / \mathrm{ml}$, the odds of AF recurrence increased by $4 \%$. NGAL is an important biomarker in clinical nephrology and might indicate chronic kidney damage. Bolignano et al. [17] pointed out that in patients with impaired renal function there is an increased baseline level of NGAL. Moreover, subjects with a higher baseline NGAL level showed an increased risk of worsening of kidney function within 1 year compared to those with lower baseline NGAL values [17]. Results from other analyses indicated that an increase of $10 \mathrm{ng} / \mathrm{ml}$ of NGAL was associated with a $2 \%$ increased risk of CKD progression, independently of eGFR and age [18].

Other clinical factors associated with AF recurrence were anemia, history of stroke and $\mathrm{LA} \geq 4.5 \mathrm{~cm}$. Anemia is known as an independent factor for new onset of AF and is associated with adverse cardiovascular outcomes [13]. The role of these factors was established in previous studies [1,3].

We would like to underline that the described correlation between MMP-NGAL complex and AF recurrence concerned only the obese population. In our population, almost half of the patients referred to cardioversion were obese. Obesity is a growing public health problem worldwide. According to the World Health Organization, more than 1.4 billion adults over 20 years of age are overweight [19]. A number of studies have demonstrated that overweight and obesity are risk factors for AF [20-22]. It is clinically important to find biomarkers of AF recurrence in this particular subpopulation. The community-based cohort study by Tsang et al. [23] showed that the greater the BMI at baseline, the higher the likelihood of progression from paroxysmal to permanent AF. In a multivariable model, a BMI $>30$ was associated with a 1.5-fold increased risk of converting to permanent $\mathrm{AF}$ [23].

Obesity is also commonly associated with comorbidities such as chronic inflammation, hypertension and diabetes, which can lead to CKD [19]. Excess adipose tissue causes hemodynamic alterations in the kidney that can contribute to renal disease [19]. Several multicenter studies have shown a correlation between obesity and renal complications [24-26]. Ejerbal et al. [25] found a 2.8-fold increased risk of nephrosclerosis and a 7-fold increased risk of diabetic nephropathy among obese adults compared with adults with a BMI within the normal range. Furthermore, even in patients without diabetes or hypertension a lifetime BMI $\geq 35$ was associated with a 2-fold increased risk of CKD [25]. The mechanisms by which obesity causes nephron injury are not fully understood and involve a combination of hemodynamic, metabolic and inflammatory changes [27].

Further larger population studies are required to validate our data and to evaluate the prognostic role of MMP-NGAL complex in patients undergoing electrical cardioversion.

\section{Conclusions}

Nowadays in everyday clinical practice, before cardioversion, we usually take into account well established factors of AF recurrence such as long-lasting AF, elderly age and enlarged left atrium, while obesity is not considered to be a disqualifying factor. It is known that the greater the BMI at baseline, the higher the likelihood of progression from paroxysmal to permanent AF. However, European Society of Cardiology (ESC) guidelines do not consider obese patients a population with a low likelihood of success of cardioversion. That is why we 
need a sensitive marker to predict sinus rhythm maintenance in such a population. In our study, we found that MMP-NGAL complex may predict AF recurrence after successful cardioversion in obese patients.

\section{Acknowledgement}

Our study was supported by the Leading National Research Center in Bialystok, Poland (KNOW).

\section{Disclosure Statement}

None of the authors have any conflicts of interest.

\section{References}

1 Camm J, Lip GY, Caterina R, et al: 2012 focused update of the ESC Guidelines for the management of atrial fibrillation: an update of the 2010 ESC Guidelines for the management of atrial fibrillation. Developed with the special contribution of the European Heart Rhythm Association. Eur Heart J 2012;33:2719-2747.

2 Nimmo C, Wright M, Goldsmith D: Management of atrial fibrillation in chronic kidney disease: double trouble. Am Heart J 2013;166:230-239.

3 Camm AJ, Kirchhof P, Lip GY, et al: Guidelines for the management of atrial fibrillation: the Task Force for the Management of Atrial Fibrillation of the European Society of Cardiology (ESC). Europace 2010;12:1360-1420.

4 Helanova K, Spinar J, Parenica J, et al: Diagnostic and prognostic utility of neutrophil gelatinase-associated lipocalin (NGAL) in patients with cardiovascular diseases - review. Kidney Blood Press Res 2014;39:623-629.

5 Hemdahl A-L, Gabrielsen A, Zhu C, Eriksson P, Hedin U, Kastrup J, Thorén P, Hansson GK: Expression of neutrophil gelatinase-associated lipocalin in atherosclerosis and myocardial infarction. Arterioscler Thromb Vasc Biol 2006;26:136-142.

6 Malyszko J, Bachorzewska-Gajewska H, Malyszko JS, Pawlak K, Dobrzycki S: Serum neutrophil gelatinase associated lipocalin as a marker of renal function in hypertensive and normotensive patients with coronary artery disease. Nephrol Carlton Vic 2008;13:153-156.

7 Gupta K, Shukla M, Cowland JB, Malemud CJ, Haqqi TM: Neutrophil gelatinase-associated lipocalin is expressed in osteoarthritis and forms a complex with matrix metalloproteinase 9. Arthritis Rheum 2007;56:3326-3335.

8 Yan L, Borregaard N, Kjeldsen L, Moses MA: The high molecular weight urinary matrix metalloproteinase (MMP) activity is a complex of gelatinase B/MMP-9 and neutrophil gelatinase-associated lipocalin (NGAL). Modulation of MMP-9 activity by NGAL. J Biol Chem 2001;276:37258-37265.

9 Lang R, Badano L, Mor-Avi V, et al: Recommendations for cardiac chamber quantification by echocardiography in adults: an update from the American Society of Echocardiography and the European Association of Cardiovascular Imaging. J Am Soc Echocardiogr 2015;28:1-39.

10 Apostolakis S, Guo Y, Lane DA, et al: Renal function and outcomes in anticoagulated patients with non-valvular atrial fibrillation: the AMADEUS trial. Eur Heart J 2013;34:3572-3579.

11 Fu S, Liu T, Luo L, et al: Different types of atrial fibrillation, renal function, and mortality in elderly Chinese patients with coronary artery disease. Clin Interv Aging 2014;9:301-308.

12 Alonso A, Lopez FL, Matsushita K, et al: Chronic kidney disease is associated with the incidence of atrial fibrillation: the Atherosclerosis Risk in Communities (ARIC) study. Circulation 2011;123:2946-2953.

$13 \mathrm{Xu} \mathrm{D}$, Murakoshi N, Sairenchi T, et al: Anemia and reduced kidney function as risk factors for new onset of atrial fibrillation (from the Ibaraki Prefectural Health Study). Am J Cardiol 2015;115:328-333.

14 Herzog CA, Asinger RW, Berger AK, et al: Cardiovascular disease in chronic kidney disease: a clinical update from Kidney Disease: Improving Global Outcomes (KDIGO). Kidney Int 2011;80:572-586.

15 Wetmore JB, Mahnken JD, Rigler SK, et al: The prevalence of and factors associated with chronic atrial fibrillation in Medicare/Medicaid-eligible dialysis patients. Kidney Int 2012;81:469-476.

16 Naruse Y, Tada H, Sekiguchi Y, et al: Concomitant chronic kidney disease increases the recurrence of atrial fibrillation after catheter ablation of atrial fibrillation: a mid-term follow-up. Heart Rhythm 2011;8:335-341.

17 Bolignano D, Coppolino G, Lacquaniti A, et al: Pathological and prognostic value of urinary neutrophil gelatinase-associated lipocalin in macroproteinuric patients with worsening renal function. Kidney Blood Press Res 2008;31:274-279.

18 Bolignano D, Lacquaniti A, Coppolino G, et al: Neutrophil gelatinase-associated lipocalin (NGAL) and progression of chronic kidney disease. Clin J Am Soc Nephrol 2009;4:337-344.

19 Felizardo RJ, da Silva MB, Aguiar CF, et al: Obesity in kidney disease: a heavyweight opponent. World J Nephrol 2014;3:50-63. 
20 Krahn AD, Manfreda J, Tate RB, et al: The natural history of atrial fibrillation: incidence, risk factors, and prognosis in the Manitoba follow-up study. Am J Med 1995;98:476-484.

21 Stewart S, Hart CL, Hole DJ, et al: Population prevalence, incidence, and predictors of atrial fibrillation in the Renfrew/Paisley study. Heart 2001;86:516-521.

22 Wilhelmsen L, Rosengren A, Lappas G, et al: Hospitalizations for atrial fibrillation in the general male population: morbidity and risk factors. J Intern Med 2001;250:382-389.

23 Tsang T, Barnes M, Miyasaka Y, et al: Obesity as a risk factor for the progression of paroxysmal to permanent atrial fibrillation: a longitudinal cohort study of 21 years. Eur Heart J 2008;29:2227-2233.

24 Fox CS, Larson MG, Leip EP, et al: Predictors of new-onset kidney disease in a community-based population. JAMA 2004;291:844-850.

25 Ejerblad E, Fored CM, Lindblad P, et al: Obesity and risk for chronic renal failure. J Am Soc Nephrol 2006;17: 1695-1702.

26 Kahn SE, Hull RL, Utzschneider KM: Mechanisms linking obesity to insulin resistance and type 2 diabetes. Nature 2006;444:840-846.

27 Hall ME, do Carmo JM, da Silva AA, et al: Obesity, hypertension, and chronic kidney disease. Int J Nephrol Renovasc Dis 2014;7:75-88. 